\title{
Body Music Courses within Music Education
}

\author{
M. Özgü Bulut \\ Anadolu University, Turkey \\ ozgubulut@yahoo.com
}

\begin{abstract}
The aim of the paper is to introduce and suggest Body Music as a significant part of music education that gives the possibility to approach music as a play of sounds and silence, from its very beginning in human life at which body was the only source of sound making, before humans created musical instruments and styles. Thus what "music" and "style" mean is briefly explained in the first part. Secondly, significant properties of body music are mentioned. Body music is emphasized as a useful practice to discover sounds, patterns and to create sound orders. This brings together the realization of the relation of body movements and sounds, which carries an introduction to moving with music or dancing; and the opportunity to practice the act of "play" in the way, which was defined by Huizinga. The last part of the paper is an introduction to a Body Music Course model concentrated on classroom activities in which an alternative notation and a syllabic body scale system are introduced, technical suggestions are made and some games of improvisation, etudes and methods, traditional rhythm patterns, body music styles and accompaniment are explained.
\end{abstract}

Keywords: Body music; Music education; Play; Music.

\section{Introduction}

Music may be defined as sounds and silence that are realized in a meaningful order. Body Music is creation of such orders with body sounds such as clapping, slapping, stepping and vocalizing (Terry, 2002). Body Music is suitable for everybody: everybody has an instrument, there is no requisition for musical talent and everybody can play Body Music in his/her own way.

Body is the natural musical instrument, which is always present in human life. It is the fundamental source of personal sound palette (body sounds) and music. Thus, Body Music is a bridge between the music of the nature and music today: the improvement path of music styles, instruments, and rhythmic structures, from the very beginning until now. It is thought that this bridge is not well emphasized in the music education programs.

The basic idea of this paper is that, adding Body Music courses to Music Education programs would be a powerful and suitable action to make this bridge clear. Focusing on the probable function(s) and status of body music in music education, this paper aims to highlight the importance to accept Body Music as a main aspect of music education in schools, which bares a potentiality to practice music with another, wider approach. Because, through the medium of Body Music, any music style may be practiced, accompanied or transmitted by playing the body as a musical instrument.

There are three sections in the paper. In the first section, the relation between "music" and "music styles" is mentioned in order to realize the presence of a style-oriented music education system and to explain what it means, "to think about music as a whole". Because, it is observed that the music education today is just connected with certain styles. In the second section some significant 
properties of Body Music that correspond to "thinking about music as a whole" are emphasized. Then, in the last section, an infinitely improvable outline of Body Music courses for school music program is given with examples, briefly mentioning the learning outcomes.

The examples in this paper are chosen to represent the main characteristics of Body Music activities. The levels of the activities are not studied in this paper. Such knowledge would be the subject of another paper based on research. Also the profile of the ideal music educator to give instructions both on Western Music Style and Body Music is not an issue of this paper.

Roughly, this paper gives the elementary information mainly to music educators, on how to utilize Body Music in the classroom. It is based on experience gained by observations and active involvement at Body Music Festivals, gatherings, concerts, and literature on body music, music education, creative drama, Orff Schulwerk, psychology of music, sociology of music, new music and human behavior.

\section{Music And Music Styles}

In this section, the relation between music and music styles and, what it means, "to think about music as a $w h o l e "$ is explained, to introduce an appropriate scope for music education.

\section{"(...) We want to be able to compare and contrast the various musics of the world. To do} that we need to think about music as a whole,"(Titon, 2009: 5).

In order to think about music as a whole, the very old question "what is music" is once again to be answered, looking through a wide compass that covers any kind and style of music and takes music as a whole. A definition of music must bring the common aspects of the various music styles of the world together. In other words, the mentioned aspects should be consistent with all different music styles. So, the question here may be: What are the common aspects of all the music styles?

A common aspect may be that music is made of sounds and silence:

"Music is sound and silence that are realized in a meaningful order. An individual may live the experience alone. Consequently, the authority to decide 'if a specific sound order is music' is an individual who realizes it just as meaningful. He/she may have made it him/herself with sounds from varying resources," (Bulut, 2010)2.

"Style includes everything related to the organization of musical sound itself: pitch elements (scale, melody, harmony, tuning systems), time elements (rhythm, meter), timbre elements (voice quality, instrumental tone color), and sound intensity (loudness/softness),"(Titon, 2009: 27).

Music education programs today mostly use the Western rules of pitch, time, timbre elements and sound intensity, which means, music education is actually applied as "education of a group of styles" that covers teaching and practicing the present Western Music styles that use 12 tones ${ }^{3}$. However, "thinking about music as a whole" is a wider approach as explained below.

\footnotetext{
${ }^{2}$ Apparently we all have ears to hear music but there are some of us who are hearing impaired but still can feel the beat, follow rhythmic structures on the body and make music. Body Music seminars are held since 2007 with the hearing impaired students in Anadolu University in Eskişehir, Turkey. The participant students play Body Music at their end-of-year concerts (Bulut, 2011: 72). Thus, in the definition above, "to realize" is the verb. Moreover, "meaning" may be anything; there is not a reason to transcribe it into words. It is a matter of subjectivity, which depends on experience and aesthetic approach.
}

${ }^{3}$ C, Cis, D, Dis, E, F, Fis, G, Gis, A, Ais, B. 


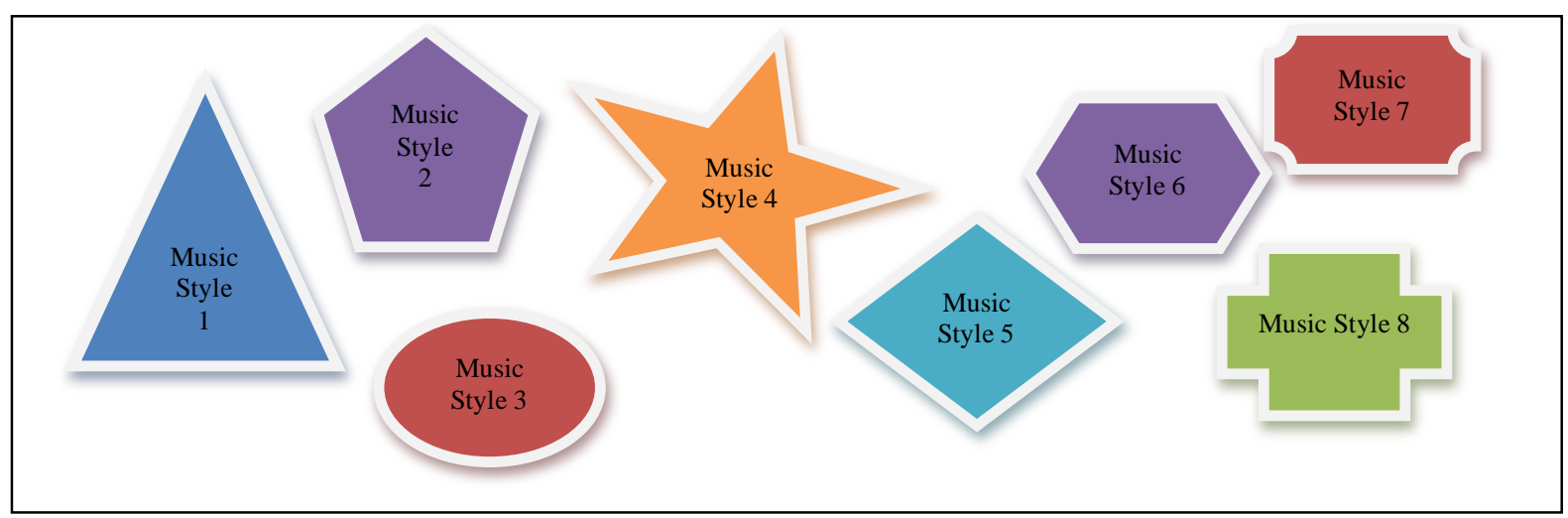

Universal Set of Music

Above, the various styles of music are represented with colored shapes in the Universal Set of Music that is represented by the rectangle surrounding them. The section around the music styles represents the "undefined" sound orders, which don't belong to any style of music; namely "music of the nature" or just made up, improvised sound orders that may have the potential to become new music styles. Actually, music styles all were formed from the materials in this part. It is thought that individual musical trials are also elements of the same part. Therefore, this part with all subjective trials is assumed to be the best beginning point for music education. The bridge mentioned in the introduction may be imagined just between the white and colored parts in the rectangle.

Briefly, music styles are subsets in the Universal Set of Music. "To think about music as a whole," means to consider music as a phenomenon with all its styles and sound orders, and variety of sounds from speech to scratching and from wind to waves and etc. "A learner who thinks about music as a whole" might be the main outcome of music education.

In Music Education it would be useful to let the learner discover, realize and develop his/her own sounds and style of music. This means to prepare the appropriate environment and accept each learner's subjective trials as music. This approach would make it easier for the learner to deal with music, as there are no prerequisites such as being able to discriminate the 12 tones or having the required physical standards to play an instrument.

\section{The Significant Properties of Body Music}

The appropriate model for Body Music courses is the Body Music workshops. At the Body Music workshops, there is a leader and participants. Each workshop has a specific title. Workshops are given either on distinct styles of Body Music such as "Hambone", "Buckdancing", "Vocal Bass and Beat-Box"; or on traditional rhythm patterns such as "Usül" and "Greek Rhythms"; or on personally achieved styles and methods such as Keith Terry's "Rhythm Blocks", Leela Petronio's "Hip-Tap", Max Pollack's "Rumba-Tap" or Sandy Silva's "Percussive Dance". Other workshops such as "Body Sounds", "Movement, Emotion, Body Sounds and Dance" and "Move Your Senses" are on discovering and developing some body and mind skills among which are making sounds, directing emotions to make sounds and movement, combining dance figures and body sounds or transforming body-sound movements to dance figures.

Body music is the action of playing with body sounds. In Body Music workshops body sounds are termed with some syllables such as bum/buma(step), dum/duma (chest), tak/taka(thighs), 
shak/shaka(clap), pat/pata (ankle), shick/shiki (finger snap)4. These syllables make it possible to keep in mind and write down the sound order of a discovered or learnt pattern on the body ${ }^{5}$ (Bulut, 2011: 45).

Body Music workshop is a "play" platform. Play is a spare time activity, has its own rules, separate from routine daily life, and its outcome is unforeseeable (Huizinga, 1955). The platform is basically an interactive medium in which a group of participants imitates the leader's movements either simultaneously as in mirroring or repetitiously as in echoing. Echoing and mirroring are the two main plays of imitation in Body Music medium. Besides these two, the leader may apply some specific methods such as Sound Painting, Creative Drama, Eurhythmics, Orff-Schulwerk and etc. or discover his/her own play models.

Body Music is both an individual and group practice of body movement, non-verbal communication, teamwork, relaxation and discovering own styles of music. As a sum of percussion, dance, vocals, speech and mimics, it is a way of self-recognition, self-expression and of musical composition and improvisation practice.

Body, as a musical instrument to practice music or to communicate, has some advantages when compared to any human-made musical instrument. There is a common set of sounds that everyone can produce and imitate and that makes it possible to play exactly the same thing at the same time together. Besides, body is in daily and life-long use. Then, Body Music is economic because there is no need to purchase an instrument and moreover it is possible to practice anywhere at any spare time without planning.

Body Music workshop is a medium that is suitable for people of any age and culture. It is the practice medium of the fundamental set of sounds that a human being can produce. It also carries some clues of music of the past and the path, which lead to the music of today. Along millenniums, this path was enlarged and civilized by music styles, instruments, systems, and etc. Body Music workshop is an access to this path of music at any chosen point especially for non-musicians. Anyone can practice some aspects of civilized music such as complex rhythmic structures, polyphony, polyrhythm and polymeter in an easy way, in short time via Body Music, within a group. Also, Body Music practice improves self-expression and gives the possibility to accompany all genres and instruments of music.

All these aspects support the idea that body music is a bridge between the music of the nature and all music styles today.

\section{A Body Music Course Model}

In this section, the fundamental aspects of a probable body music course are explained. At first, there are technical suggestions that help to use the arms, legs and the body with less energy and power. Secondly, subject-contents of the course are grouped under 5 main titles that are "improvisation", "etudes and methods", "traditional rhythm patterns", "body music styles" and "body music accompaniment".

\section{Technical Suggestions}

The technical guidelines to be given to the class are:

\footnotetext{
${ }^{4}$ Some step-dancers use chee/kee and boom for toe/back and step; some other use the syllables tap-step-toe-chug and ball.

5 The mentioned syllables are used at the examples in the following chapter of this paper.
} 
1. Never expect to produce loud sounds on the body. Be as soft as possible with all your body movement. Audible or not, every movement has its sound. It will be there in any case.

2. Do not hit but drop your hands -on each other, your chest, thighs, etc.- Feel the weight of your arms and legs. Realize that your whole body weight is on one leg when you are playing the ground with the other foot. Each step is a weight transfer.

3. Do not lock your knees, do not stand still, let your body and parts sway and swing.

4. Never stop moving in between body sounds you make. Watch the continuous action of your arms and hands moving from one spot to another.

\section{Subject-Contents}

\section{a) Improvisation}

An effective way to discover "body sounds, noise, silence, directing emotions towards movement, combining dance figures and body sounds, transforming body-sound movements to dance figures, playing rhymes on body sounds, playing poems on body sounds", is improvisation.

There are some examples of group improvisation games below:

\section{"Spiral"6}

The group is shaped into a spiral form. The leader stands in the inner beginning point and starts a simple repeating pattern with a steady pulse. The participants join one by one with improvised easy repeating patterns. When the entire group joins in, everybody stops playing one by one starting from the leader.

\section{"Circle Games"}

Circle games are easy but effective for practicing short solo improvisations. A simple form of circle games is one by one clapping while the group stands in circle shape. Another version may be: Everybody in the circle introduce themselves one by one -only saying his/her name out- in a rhythmic, theatrical, energetic, whispering, etc. way with a movement. At the second turn everyone makes just one body sound. It is forbidden to repeat the previous person's move. At the third turn, everyone makes two sounds; at the fourth, three sounds...and it continue. These may all occur while walking simultaneously in circle shape.

For the learner, these group and individual improvisation games are practices to discovering the own sound-ID, acting in front of an audience, turn taking, observing other students while improvising, playing together in tempo, producing music together, working within a group and self-expression. Music education, when done with the body, has a wide scope that it even covers all behaviors. Because there is no other special tool - a musical instrument - designed just for music making in between the learners and the meaningful sound orders they produce.

\section{"Order and Chaos"}

Some sound textures are easy to produce when a group of people is asked for simultaneous action. For example murmuring, talking pseudo, going "ssss..." or "aaaaa..." or "hhh...", coughing, crying, laughing, playing percussive body sounds, remaining silent, in loud, soft, angry, tranquil manners.

\footnotetext{
${ }^{6}$ Fernando Barba introduced this group improvisation game at $5^{\text {th }}$ Body Music Festival in İstanbul (October
} 2012). 
Some of these textures are order and others are chaos. A number of these textures are enough material to compose a piece by conducting, when there are certain assignments of bodily signs to certain textures, manners or loudness and softness. Sounds such as a thunderstorm, rain, thunderclaps, machines, animals, cries, laughs, sighs, vowels, whispers, shouts, speeches, screams, slogans, etc. may be made altogether in the class. Sound Painting is such a method of sign language that may be useful to practice in this case.

Such practices serve to make the learner realize that; there are possibilities to reach an order in large scale made by a variety of orders and chaos.' Orders and chaos' may be used as parts in musical forms to create music pieces with a crowd. For example, a Rondo ( $A B A C A$ ) may be composed as such:

A: a sentence made from short and long, loud and soft vowels (a, e, i, o, u).

B: a mass of body sounds

C: a sentence made from short and long, loud and soft consonants and/or syllables ( $\mathrm{s}$, sh, zz..., rrr..., ta!, tja!, dun!,...)

In musical terms, this is a practice of form analysis, which is as well a larger scale rhythmic structure.

\section{b) Etudes and Methods}

\section{"Shiki-shiki".}

\begin{tabular}{|c|c|c|c|c|c|c|c|c|c|c|c|c|c|c|}
\hline (Beat) & 1 & & & 2 & & & & 3 & \multirow{2}{*}{\multicolumn{2}{|c|}{ KI }} & \multicolumn{2}{|l|}{4} & \\
\hline Snap & SHI & KI & & SHI & & KI & & SHI & & & SHI & & \multicolumn{2}{|l|}{ KI } \\
\hline Clap & SHAK & & & $\mathrm{SHA}$ & & & & SHAK & & & SHA & & & \\
\hline Thighs & \begin{tabular}{l|l} 
DA & GA \\
\end{tabular} & DA & GA & DA & GA & DA & GA & \begin{tabular}{l|l|} 
DA & GA \\
\end{tabular} & DA & GA & DA & GA & DA & GA \\
\hline Step & BUM & & & & & & & BUM & & & & & & \\
\hline
\end{tabular}

This is an etude to practice 16th, 8th and quarter notes explained by Doug Goodkin ${ }^{7}$ at a workshop. The finger-snaps give the 8th's; claps the quarters; thighs the sixteenths; and steps the half notes after each other. The order of the body sounds is chosen in an top-to-bottom order. Seeing and hearing the pattern simultaneously ${ }^{8}$ makes it easy to memorize. This pattern is suitable for canon in 2 or 4 groups.

In terms of music education, besides being a practice of half, quarter, $8^{\text {th }}$ and $16^{\text {th }}$ note rhythms and their relation, this etude is useful for canon practice and may also be varied in other meters.

\section{"Cross" or "Thighs"}

\begin{tabular}{|l|l|l|l|l|l|l|l|l|}
\hline $\begin{array}{c}\text { Beat } \\
\text { Division }\end{array}$ & 1 & & 2 & & 3 & & 4 & \\
\hline $1-.$. & TAK & TAK & TAK & TAK & TAK & TAK & TAK & - \\
\hline $2-2-2-2$ & TAK & SHAK & TAK & SHAK & TAK & SHAK & TAK & - \\
\hline $3-3-2$ & TAK & SHAK & SHIK & TAK & SHAK & SHIK & TAK & - \\
\hline $3-3-2$ & TAK & IAK & TAK & SHAK & SHIK & SHAK & TAK & - \\
\hline
\end{tabular}

"TAK": Both arms beat on the thighs at the same time, SHAK: Hand -clap, SHIK: Snap fingers both at the same time.

\footnotetext{
${ }^{7}$ An expert of Orff Schuwerk, director and teacher in San Francisco Music School.

8 "Music you can see, dance you can hear", the booklet of 4th Body Music Festival in California Bay Area in the first week of November 2011.
} 


\section{"TAK": Cross the arms and beat on both thighs at the same time: right hand on the left thigh and vice versa.}

It is also possible to use the variation techniques applied to the Shikishiki game explained before. Those two games also fit well to be played together as they are both in $4 / 4$ time. The first may be played either 1 or 2 times over the latter which is useful to form different polyphonic variations.

This etude is a practice to get used to even and odd number of beats that form a rhythmic pattern. This is how the irregular meters are formed. Here, the first and second lines are regular but third and fourth are irregular divisions. Second and third lines may be used to raise the awareness in a 2:3 rhythmic pattern.

\section{"Chocolade"}

This is a Chilean Children's Game introduced by Goodkin (2008: 16).

Another tool to use with body music is the language. Prosody in any language is full of varieties of rhythmic patterns. Rhymes work well in this case.

\begin{tabular}{|c|c|c|c|c|c|c|c|c|c|c|c|c|}
\hline $\begin{array}{l}\text { (Beat) } \\
\rightarrow\end{array}$ & 1 & & 2 & & 3 & 4 & 1 & & 2 & & 3 & \\
\hline Rhyme & Cho- & co & Cho- & co & la & la & Cho- & Co & Cho- & Co & de & de \\
\hline Pat & Pat & & Pat & & $\begin{array}{l}\text { Pat } \\
\text { Back }\end{array}$ & $\begin{array}{l}\text { Pat } \\
\text { Back }\end{array}$ & Pat & & Pat & & $\begin{array}{l}\text { Pat } \\
\text { Fist }\end{array}$ & $\begin{array}{l}\text { Pat } \\
\text { Fist }\end{array}$ \\
\hline
\end{tabular}

\begin{tabular}{|c|c|c|c|c|c|c|c|c|c|c|c|}
\hline (Beat) & \multicolumn{2}{|l|}{1} & 2 & \multicolumn{2}{|l|}{3} & 4 & \multicolumn{2}{|l|}{1} & 2 & 3 & 4 \\
\hline Rhyme & Cho- & co & la & Cho- & co & de & Cho- & co & la & de & - \\
\hline Pat & Pat & & $\begin{array}{l}\text { Pat } \\
\text { Back }\end{array}$ & Pat & & $\begin{array}{l}\text { Pat } \\
\text { Fist }\end{array}$ & Pat & & $\begin{array}{l}\text { Pat } \\
\text { Back }\end{array}$ & $\begin{array}{l}\text { Pat } \\
\text { Fict }\end{array}$ & - \\
\hline
\end{tabular}

Pats may be on the thighs, on the floor or standing face-to-face on each other's hands. Many other words may be discovered that fit in this rhythmic pattern such as lemonade or serenade. Patting quarter beats while speaking eighths give the opportunity to practice dividing time in two. It is also possible to pat the rhythm of the rhyme:

\begin{tabular}{|l|l|l|l|l|l|l|l|l|l|l|l|l|}
\hline $\begin{array}{l}\text { (Beat) } \\
\rightarrow\end{array}$ & 1 & & & & 4 & 1 & & 2 & 3 & 4 \\
\hline Rhyme & Cho- & co & Cho- & co & la & la & Cho- & co & Cho- & Co & de & de \\
\hline Pat & SHI & KI & SHI & KI & SHAK & SHAK & SHI & KI & SHI & KI & TAK & TAK \\
\hline
\end{tabular}

\begin{tabular}{|l|l|l|l|l|l|l|l|l|l|l|l|}
\hline $\begin{array}{l}\text { (Beat) } \\
\rightarrow\end{array}$ & 1 & & & 3 & 4 & 1 & 2 & 3 & 4 \\
\hline Rhyme & Cho- & co & la & Cho- & co & de & Cho- & co & la & de & - \\
\hline Pat & SHI & KI & SHAK & SHI & KI & TAK & SHI & KI & SHAK & TAK & - \\
\hline
\end{tabular}

This rhyme may be a step prior to Shiki-shiki. Because; it has only the variations of rhythmic motives formed with $8^{\text {th's }}$ and quarter notes. Its relationship with language supports the fact that when one can sing a rhythmic pattern, he/she can play it, too. A further step is transcription of the rhyme into body sounds. This is a translation process from language to rhythm and a way to realize of how complex the rhythmic structures produced while talking are. Consequently, the reality that any rhyme or sentence may be translated into body sounds may be a useful hint for improvisation. Then, there is no doubt that the universal set of music also includes speech. 


\section{"Rhythm Blocks"}

This is a method introduced by Keith Terry in 1978 who discovered an easy-to-move sound order on his body:

"If we start with a single clap(C) and move down on the body, the next available sound will be produced by striking the chest. Strike with the right hand $(R C)$, then the left ( $L C)$ in the center of the sternum. You will know when you are playing the correct spot as the whole chest will resonate with a rich tone. Strike and release. Next come the thighs (RT) (LT), which you strike on the front or side. There is no need to reach lower than the natural extension of your arms. This is followed by the hips $(R H)(L H)$. Be certain to make a distinction between the thighs and hips; they create different sounds and the visual contrast is important when considering the movement. The sounds from the feet (RF) (LF) are produced by low, flat-footed, grounded steps with a minimum of extraneous movement," (1989).

Keith Terry suggests this order as a technical body etude for daily practice. Besides, in this etude there are 9 Rhythm Blocks that may be played in loops:

\begin{tabular}{|c|c|c|c|c|c|c|c|c|c|}
\hline BodyParts & Clap & $\begin{array}{l}\text { R } \\
\text { Chest }\end{array}$ & $\begin{array}{l}\text { L } \\
\text { Chest }\end{array}$ & $\begin{array}{l}\text { R } \\
\text { Thigh }\end{array}$ & $\begin{array}{l}\text { L } \\
\text { Thigh }\end{array}$ & R Hip & L Hip & R Foot & L Foot \\
\hline BodySounds & SHAK & DUM & DUM & TAK & TAK & PAT & PAT & BUM & BUM \\
\hline $\begin{array}{l}\text { (Beat) } \rightarrow \\
\text { Block }\end{array}$ & 1 & 2 & 3 & 4 & 5 & 6 & 7 & 8 & 9 \\
\hline 9 & SHAK & DUM & DUM & TAK & TAK & PAT & PAT & BUM & BUM \\
\hline 8 & SHAK & DUM & DUM & TAK & TAK & PAT & PAT & BUM & \\
\hline 7 & SHAK & DUM & DUM & TAK & TAK & PAT & PAT & & \\
\hline 6 & SHAK & DUM & DUM & TAK & TAK & PAT & & & \\
\hline 5 & SHAK & DUM & DUM & TAK & TAK & & & & \\
\hline 4 & SHAK & DUM & DUM & TAK & & & & & \\
\hline 3 & SHAK & DUM & DUM & & & & & & \\
\hline 2 & SHAK & DUM & & & & & & & \\
\hline 1 & SHAK & & & & & & & & \\
\hline
\end{tabular}

With these blocks, any regular and irregular meter may be practiced in loops. Variations of $8 / 8$ may be played as $[2+2+2+2],[3+3+2],[3+2+3],[2+3+3],[5+3],[3+5],[2+6],[6+2]$ or $[4+4]$. It is possible to use the blocks to play a variety of poly-meter loops with the group.

One of the poly-meter loops directed by Terry in some workshops is, "Hey! You! Who? Me? What". It is for four groups.

\begin{tabular}{|c|c|c|c|c|c|c|c|c|c|c|c|c|}
\hline $\begin{array}{l}\text { (Beat) } \\
\rightarrow\end{array}$ & 1 & 2 & 3 & 4 & 5 & 6 & 7 & 8 & 9 & 10 & 11 & 12 \\
\hline Group1 & Hey & & & You! & & & & & & & & \\
\hline $\begin{array}{l}\text { BI.(3+9 } \\
\text { ) }\end{array}$ & $\begin{array}{l}\text { SHA } \\
K\end{array}$ & $\begin{array}{l}\text { DU } \\
M\end{array}$ & $\begin{array}{l}\mathrm{DU} \\
\mathrm{M}\end{array}$ & $\begin{array}{l}\text { SHA } \\
K\end{array}$ & $\begin{array}{l}\text { DU } \\
M\end{array}$ & DUM & TAK & TAK & PAT & PAT & BUM & BUM \\
\hline Group2 & Hey & & & & & $\begin{array}{l}\text { Who } \\
?\end{array}$ & & & & & & \\
\hline $\begin{array}{l}\text { Bl.(5+7 } \\
\text { ) }\end{array}$ & $\begin{array}{l}\text { SHA } \\
K\end{array}$ & $\begin{array}{l}\text { DU } \\
M\end{array}$ & $\begin{array}{l}\text { DU } \\
M\end{array}$ & TAK & TAK & SHAK & $\begin{array}{l}\text { DU } \\
M\end{array}$ & DUM & TAK & TAK & PAT & PAT \\
\hline Group3 & Hey & & & & & & & Me! & & & & \\
\hline $\begin{array}{l}\text { Bl.(7+5 } \\
\text { ) }\end{array}$ & $\begin{array}{l}\text { SHA } \\
K\end{array}$ & $\begin{array}{l}\text { DU } \\
M\end{array}$ & $\begin{array}{l}\text { DU } \\
M\end{array}$ & TAK & TAK & PAT & PAT & $\begin{array}{l}\text { SHA } \\
K\end{array}$ & $\begin{array}{l}\text { DU } \\
M\end{array}$ & DUM & TAK & TAK \\
\hline Group4 & Hey & & & & & & & & & $\begin{array}{l}\text { What } \\
\text { ? }\end{array}$ & & \\
\hline $\begin{array}{l}\text { Bl.(9+3 } \\
\text { (9) }\end{array}$ & $\begin{array}{l}\text { SHA } \\
K\end{array}$ & $\begin{array}{l}\text { DU } \\
M\end{array}$ & $\begin{array}{l}\text { DU } \\
M\end{array}$ & TAK & TAK & PAT & PAT & BUM & BUM & SHAK & $\begin{array}{l}\text { DU } \\
M\end{array}$ & $\begin{array}{l}\text { DU } \\
M\end{array}$ \\
\hline
\end{tabular}


All the groups play their part at the same time and shout out the lyrics at the same time with their claps. An irregular 12 of $[3+2+2+2+3]$ is heard with a dialogue. On the other hand there are polymeters going on in the loop, which collapse at "hey"every 12 beats. It is possible to create pieces of this kind with different blocks, with less or equal number of groups. All is mathematical calculation. This time cha, che, chi and chu may be shouted out at the claps.

Poly-meter and poly-rhythm are of the musical terms that a non-musician would hardly experience. However, with the help of rhythm blocks, this terminology may come into music education in schools and this helps the learner grasp what goes on in many of the $20^{\text {th }}$ Century repertoire works such as Stravinski's "Petrouchka" or Bartok's "Wonderful Mandarin". These terms are also rhythmic definitions of the loops of the planets and satellites giving the clues of how their movements could be transcribed into music. The significant point here is that, body music enables the learner to approach musical composition as a reflection of his surroundings.

\section{c) Traditional Rhythm patterns}

\section{"Usul"}

Ottoman rhythmic pattern loops named usuP, are usually played on percussion instruments of Ottoman culture such as kudüm ${ }^{10}$ and bendir ${ }^{11}$. However usuls may be played on the body easily. There are specified names for the pitches in usu/practice. The heavy beat is represented with a düm, (dï $\boldsymbol{m e}$ ) whereas moderate and light beats are represented by tek, hek, te ke, tek kâ, ta hek upon the pitch level (Bektaş, 2005: 3; Özkan, 2003: 608). As shown in the notation below, Yürük Semai loop is as written on the first line and it may be transcribed to body music as on the second line.

\begin{tabular}{|l|l|l|l|l|l|l|}
\hline & 1 & 2 & 3 & 4 & 5 & 6 \\
\hline $\begin{array}{l}\text { Yürük } \\
\text { Semai }\end{array}$ & DÜM & TEK & TEK & DÜM & TEK & - \\
\hline $\begin{array}{l}\text { Body } \\
\text { sounds }\end{array}$ & BUM & SHAK & SHAK & BUM & SHAK & - \\
\hline
\end{tabular}

Body sounds used above could have been other two choices such as shak and shik or dum and tak respectively for the low and high pitches. Once the learners tap either this loop or other loops from other cultures on their body they will have access to a worldwide rhythmic pattern literature. The example above is one of the simplest; in every music culture there are basic rhythms that beginners can tap easily. Maybe this application of body music would be a rational introduction to ethnomusicology (even at primary school level).

Almost every tradition has its rhythmic patterns as a part of cultural inheritance. These patterns give important information about the people of that tradition. Learning each other's patterns feed the intercultural relations and helps to getting to know each other better. It takes much shorter time than learning a melody or the language. Learning to play the percussion instrument of a tradition and getting one may be difficult but transcribing its patterns into body music helps to imitate and remember them. As for music learners, these patterns extend their vocabulary and make them much familiar with any sort of music they hear. In this way it is much easier to keep in step with people from other lands.

\footnotetext{
${ }^{9}$ Usuls are ostinato patterns that keep on looping throughout any Turkish Classical Music piece. There are hundreds of them in many different meters and tempi.

${ }^{10}$ Two high-low kettle drums more or less at the size of bongos.

${ }^{11}$ Frame drum.
} 
For example how to play for example Brazilian, African, Indian, Turkish, Spanish Rhythmic patterns such as Tumbao, Mozambique, Tala, Usul and those of Flamenco may be learnt by imitation on the body.

\section{d) Body Music Styles}

There are some Body Music Styles formed through centuries in various parts of the world. Some of them have begun as movements against racist acts (Hambone, Patting Juba, African Gumboots), some have been improved as part of social or secular life (Tuvan, Inuit and European Harmonic and Throat Singing Styles, Kecak, Irish Step Dancing, Buck Dancing (Southern Appalachian Clogging, Flatfooting), Vocal Bass, Beat-Box). Also there are some others, which have been developed by individual attempts that have gained popularity in the recent years such as Leela Petronio's "Hip-Tap", Max Pollack's "Rumba-Tap", Keith Terry's "Body Tjak", Tugay Başar's "KeKeÇa" or Sandy Silva's "Percussive Dance".

Hambone is one of these styles that arose when playing drums and loud instruments were forbidden to the slaves after the Slave Rebellion in 1739.

"... Hambone is a beat done with your palms hitting your chest or legs; slap-lacka-slaplacka-slap-slap," (Mooney, 2009: 55).

There are three main Hambone patterns. The first pattern is with a clap (SHAK) and two chests (DUDUM) in a shuffle mood (triplets). At the second pattern (sitting down) hands play on the thighs as follows: right hand goes down and up between right thigh and palm of left hand that rests motionless just above the right thigh (TA-KI-TA) and then left hand goes down and up between left thigh and right hand (TA-KI-TA). The pattern continues with alternating beats on the thighs. The third pattern (sitting down) begins with both hands on the back thighs (SLAP) going up to the chest (LACK), dropping down on the thighs $(A)$ (palms up) and repeating.

\begin{tabular}{|c|c|c|c|c|c|c|c|c|c|c|c|c|c|c|c|c|}
\hline $\begin{array}{r}\text { Beat } \\
\text { Pattern }\end{array}$ & \multicolumn{2}{|l|}{1} & & & \multicolumn{2}{|l|}{2} & & & \multicolumn{2}{|l|}{3} & & & \multicolumn{2}{|l|}{4} & \multirow[b]{2}{*}{$\mathrm{SH}$} & \multirow[b]{2}{*}{ D } \\
\hline 1 & $\mathrm{D}$ & & $\mathrm{SH}$ & $D$ & D & & $\mathrm{SH}$ & $\mathrm{D}$ & $D$ & & SH & $\mathrm{D}$ & $\mathrm{D}$ & & & \\
\hline 2 & TA & $\mathrm{KI}$ & TA & TA & KI & TA & TA & $\mathrm{KI}$ & TA & TA & KI & TA & TA & KA & TA & $\mathrm{KA}$ \\
\hline 3 & \multicolumn{2}{|c|}{ SLAP } & & & \multicolumn{2}{|c|}{ SLAP } & \multicolumn{2}{|c|}{ LACK } & \multicolumn{2}{|l|}{$A$} & \multicolumn{2}{|c|}{ SLAP } & \multicolumn{2}{|c|}{ LACK } & \multicolumn{2}{|l|}{$A$} \\
\hline Lyrics & \multicolumn{2}{|c|}{ HAM } & & & \multicolumn{2}{|c|}{ BONE } & & & \multicolumn{2}{|c|}{ HAM } & & & \multicolumn{2}{|c|}{ BONE } & & \\
\hline
\end{tabular}

Hambone is traditionally played as accompaniment to some 7-syllable rhymes such as

"Hambone, hambone / where've you been?

'Round the world and / back again..."

Like Hambone, all of the percussive styles have their significant characteristics of playing rhythm and moving the body. As they are all suitable to accompany any music style, they are useful for any music learner to grasp the rhythmic skeleton of any music they hear. Some are results of interesting stories that may be helpful for the learner to understand how and why people express themselves in terms of music and dance. Learning these styles is also an introduction to ethnic music in a direct way, because the instrument and movement remains the same as the original. Besides, despite how complex the patterns are, learning to play them on the body is much more natural then on drums or in theory because the body is a living drum: It feels the rhythm as you play on it. Moreover, there are ergonomic body movements that help to play the patterns and keep them in mind easily. 
However, like many music styles, some of these styles such as throat singing require to be talented and patient. Anyway, the percussive ones are suitable for any learner.

\section{e) Body Music Accompaniment}

Moving the body towards sounds enables learners gain the capability to feel all sounds around with their body and therehow help to develop their emotional approaches, organize their kinestetic habits and enrich their field of imagination. Also rhythmic education of body and mind has affects on the formation of a mediative character (Dalcroze, 1930).

At Eurhythmics practice of Dalcroze, there is an exercise of simultaneous duo dance accompaniment to a duo music piece. For example, while a flute-cello duet is performed or played on tape, the first dancing group/person reacts to the rhythm of the flute and the second, to that of the cello. When music is a trio, the class is divided into three groups. This exercise is also possible with individuals instead of groups. The same practice may be applied with body sounds or percussive dance figures (Bulut, 2011 - 2).

Body is always suitable as a solo or accompanying instrument to the music of any culture and style. A useful practice within music education is to accompany any musical instrument or recording with body sounds, apart from only snapping or clapping the metronome. This action lets the learners discover the way they like to move to music or get into dialogue with any musical instrument. In both cases, learners practice to harmonize with another musician. The same practice may be with a choir and body orchestra in a class.

\section{Conclusion}

Body Music courses serve as a guide of the body sounds and movements. They provide a platform to practice cerebral activities. The content of these courses are related to every sound-related move and behavior in human life, which is a very wide compass.

The course is an interactive learning environment to play musical games either alone or accompanied. The activities of Body Music courses help to explain almost all issues of music lessons in an easier and enjoying way. Besides, giving Body Music courses within music education is a way to introducing music to the learner in a wider scope. It is boundary expanding and encouraging for the learners either in presenting themselves, speaking in public, being on stage, being a performer or evaluating others' movements and sounds. For the music educator, giving Body Music Courses is to approach the body as a musical instrument to play with body sounds, mimics, gestures, speech and movements. It is also a different approach to music education as a platform to investigate and explore self-aesthetics and limits in making sounds and movements.

Music education, when done with the body, has such a wide scope that it even covers all the body movements, which also have effects on all behaviors. Because there is no other "special tool" - a human made musical instrument designed just for music making - in between the learners and their music.

Body music is suitable as an educational tool for founding a bridge between the very beginning and this moment of music making. Body Music courses are useful to prevent the alienation between man and his music that was explained by Adorno (Oskay, 2001; Paddison 1998).

\section{References}

Bektaş T. (2005) Relationships between Prosodic and Musical Meters in the Beste Form of Classical Turkish Music. Asian Music; 36 (winter), 1. 
Bulut, M.Ö. (2011) Kalabalıklar ve Beden Müziği. (Crowds and Body Music) Thesis -Expertise in Arts. Eskişehir: Anadolu University Instititute of Fine Arts.

Bulut, M.Ö. (2011) Atölye: "Duygularınızı Harekete Geçirin". In Neo Filarmoni Issue 4: July-August. Ankara: Dumat Ofset.

Bulut, M.Ö. (2010) Body Music and Socio-Cultural Change. In Music and Music Education within the Context of Socio-Cultural Changes. Ed. N. Kalyoncu, D. Erice, M. Akyüz. Ankara: Müzik Eğitimi Yayınları.

Dalcroze, E. J. (1930) Eurythmics, Art and Education. (Trans . Rothwell, F., ed. Cox, C). London: Chatto and Windus.

Goodkin, D. (2008) Intery Mintery Nursery Rhymes. San Francisco, CA: Pentatonic Press.

Huizinga, J. (1955) Homo Ludens: A Study of the Play Element in Culture. Boston, Massachussetts:Beacon Press.

Mooney, P. (2009) Black is the New White. New York, NY: Simon and Schuster.

Oskay, Ü. (2001) Müzik ve Yabancılaşma (Music and Alienation). İstanbul: Der Yayınları.

Özkan, İ.H. (2003) Türk Musikisi Nazariyatı ve Usülleri (Turkish Music Theory and Usüls). Ankara: Ötüken Neşriyat.

Paddison, M. (1998) Adorno's Aesthetics of Music. Cambridge: Cambridge University Press.

Terry, K. (2002) Body Music with Keith Terry Part One. Instructional DVD. Oakland, CA: Crosspulse Media.

Terry, K. (1989) Body-Music Keith Terry.pdf (1989). http://www.teaching.crosspulse.com/ [accessed on 24.11.2011, 22.15 hrs].

Titon, J. T.(2009) Worlds of Music: An Introduction to the Music of the World's Peoples, Shorter Version. Rhode Island: Cengage Learning. 